\title{
Fatty acid hydroxylase-associated neurodegeneration
}

INSERM

\section{Source}

INSERM. (1999). Orphanet: an online rare disease and orphan drug data base. Fatty acid hydroxylase-associated neurodegeneration. ORPHA:329308

Fatty acid hydroxylase-associated neurodegeneration (FAHN) is a very rare, autosomal recessive form of neurodegeneration with brain iron accumulation (NBIA) characterized by childhood-onset focal dystonia, progressive spastic paraplegia that progresses to tetra paresis, ataxia, dysarthria, intellectual decline, and oculomotor disturbances (optic atrophy), accompanied by iron deposition in the globus pallidus. 